\title{
ESPECIFICIDADE DA DOCÊNCIA NO INSTITUTO FEDERAL DE EDUCAÇÃO, CIÊNCIA E TECNOLOGIA DO ESPÍRITO SANTO (IFES)
}

\author{
SPECIFICITY OF TEACHING AT THE INSTITUTO FEDERAL DE EDUCAÇÃO, CIÊNCIA E \\ TECNOLOGIA DO ESPÍRITO SANTO (IFES)
}

ESPECIFICIDAD DE LA ENSEÑANZA EN EL INSTITUTO FEDERAL DE EDUCAÇÃO,
CIÊNCIA E TECNOLOGIA DO ESPÍRITO SANTO (IFES)

Tatiana das Merces

(SEEduc/ES, Brasil)

Marcelo Lima

(UFES, Brasil)

\section{doi) https://doi.org/10.29404/rtps-v5i8.356}

RESUMO: 0 artigo aponta especificidades do Instituto Federal de Educação, Ciência e Tecnologia do Espírito Santo (IFES) e suas implicações para a docência. Este artigo é um excerto de pesquisa sobre a docência na Educação Profissional que toma como referência teórica o potencial emancipatório do trabalho e seu caráter educativo, cuja centralidade é a formação humana para a crítica e a autonomia. Os dados permitem identificar que o IFES possui um modus operandi bastante arraigado: a docência encontra-se sob forte influência dos ditames institucionais e culturais; seus valores, finalidades, objetivos, currículo escolar, entre outras prescrições, são alguns dos elementos que influenciam a prática pedagógica dos professores, adequando-a segundo as proposições institucionais.

Palavras-Chave: Docência, Educação Profissional, Rede federal de educação tecnológica, Pedagogia da autonomia.

ABSTRACT: this paper points out specificities of the Instituto Federal de Educação, Ciência e Tecnologia do Espirito Santo (IFES) and its implications for teaching. This paper is an excerpt from research on teaching in Professional Education that takes the potential emancipatory of work and its educative character as a theoretical reference, whose centrality is human formation for criticism and autonomy. The data allow us to identify that IFES has a very entrenched modus operandi: teaching is under strong influence of institutional and cultural dictates; their values, purposes, objectives, school curriculum, among other prescriptions are some of the elements that influence the pedagogical practice of teachers, adapting them according to institutional propositions.

Keywords: Teaching, Professional Education, Federal technological education network, Pedagogy of autonomy.
RESUMEN: el artículo señala las especificidades del Instituto Federal de Educación, Ciencia y Tecnología de Espírito Santo (IFES) y sus implicaciones para la enseñanza. Este artículo es un extracto de una investigación sobre la enseñanza en Educación Profesional que toma como referencia teórica el potencial emancipador del trabajo y su carácter educativo, cuya centralidad es la formación humana para la crítica y la autonomía. Los datos nos permiten identificar que el IFES tiene un modus operandi muy arraigado: la enseñanza está bajo la fuerte influencia de los dictados institucionales y culturales; Sus valores, propósitos, objetivos, currículum escolar, entre otras prescripciones, son algunos de los elementos que influyen en la práctica pedagógica de los docentes, adaptándola de acuerdo con las proposiciones institucionales.

Palabras Clave: Docencia, Educación Profesional, Red Federal de Educación Tecnológica, Pedagogía de la Autonomía. 


\section{A especificidade do trabalho docente}

O aporte teórico que subsidia esta pesquisa é composto, principalmente, por Machado (2008), Moura (2014), Kuenzer (2011), educadores que contribuem para a compreensão de que a docência na educação profissional ultrapassa a formação de pessoas para o mercado. Logo, trata-se de um trabalho complexo, desafiador e atravessado pelas contradições inerentes ao sistema capitalista.

Para esses autores, o professor possui certo grau de autonomia para refletir sobre a sua prática pedagógica e para trabalhar visando à superação da lógica do capital que reduz a educação aos interesses do mercado. Nesse sentido, Kuenzer (2011) destaca que o trabalho docente é implicado pelas contradições inerentes ao sistema capitalista. Isto é, ao mesmo tempo em que a educação escolar é tida como instrumento do capital, é também concebida pelos trabalhadores como um espaço privilegiado para a apropriação de conhecimentos científicos e filosóficos produzidos pelas gerações anteriores. Sendo assim, o professor é orientado a atuar de forma coerente com a ideologia capitalista, formando profissionais para atender ao mercado, mas, também é convocado a atuar em prol do desenvolvimento dos seres humanos, preparando-os para sua inserção na prática social.

Kuenzer (2011) afirma ainda que é possível agir no sentido da formação humana, principalmente quando o professor consegue promover situações que possibilitam a seus alunos saírem do senso comum e alcançarem a consciência filosófica. Portanto, diante do papel social da educação escolar, a função do professor não se resume à formação de trabalhadores conforme o modo de produção capitalista, cabendo ao professor dirigir, organizar e planejar sua atividade de ensino tendo em vista a formação ampla, crítica e política dos cidadãos.

Gomes e Martins (2004) explicam que ser professor significa participar da emancipação, da liberdade e da independência das pessoas. A função do docente, portanto, é transformar os alunos permitindo-lhes uma atuação reflexiva no mundo. Para tanto, segundo Moura $(2000,2016)$, o professor precisa ensinar; essa é a atividade principal do professor. $\mathrm{O}$ autor defende que a atividade de ensino deve ter como objetivo central permitir aos alunos desenvolverem a atividade de aprendizagem, isto é, aproximá-los dos conhecimentos construídos histórica e socialmente pela humanidade. Se isso não acontece, a prática educativa não tem sentido.

Sobre o trabalho docente, Moura $(2000,2016)$ mostra que ele possui uma natureza particular, o que permite afirmar que a atuação de um profissional técnico ou engenheiro é bem diferente da atuação do professor, pois ainda que ambos possuam o mesmo objeto (a mecânica), mas agem sobre ele de modo distinto, pois a finalidade dos dois é diferente.

No contexto da mecânica, por exemplo, o engenheiro precisa projetar, construir, operar os sistemas mecânicos, mas o professor precisa realizar a atividade de ensino: ensinar a projetar, construir e operar os sistemas mecânicos. Logo, para ser professor de mecânica é necessário saber transformar o conhecimento tecnológico em conteúdo 
escolar. Em outras palavras, ao professor é necessário não só saber as regras que implicam a profissão na área da mecânica, mas saber ensiná-las, tendo em vista o aprendizado por parte dos alunos. Essas reflexões se estendem para todas as áreas de ensino, ou seja, ensinar matemática, língua portuguesa, eletricidade, entre outros conhecimentos é diferente de ser um matemático, um linguista e um eletricista, posto que o foco do professor é o aprendizado do seu aluno.

O produto do professor é o seu aluno (ser humano) transformado. Como afirma Moura (2016), no processo educativo, o aluno tende a sair diferente de como entrou, isto é, ao aprender, o aluno se transforma, e essa transformação não se conserva apenas no momento da aula, mas se estende por toda a vida dele.

Contudo, não é somente o aluno que se transforma, no processo de ensino e aprendizagem o professor também é transformado. Trata-se da dialética do trabalho, em que o trabalho possibilita não somente a transformação dos objetos (ou produtos), mas promove a transformação do próprio trabalhador. Nessa lógica, o professor também sai diferente da aula, e sua identidade profissional se constitui pela função que ele exerce: ele é educador porque educa.

Em comum, esses autores favorecem o entendimento de que trabalho docente é muito mais que propiciar conhecimentos. Sendo a educação um instrumento político e de luta, a prática docente, na mesma lógica, é uma mediação política e de luta. Nesse sentido, é de suma importância que o professor tenha consciência que o seu trabalho não é neutro na sociedade. Como exposto, o professor trabalha em função da aprendizagem dos alunos, que remete à apropriação dos saberes, da ciência, da filosofia e da arte, construídos histórica e socialmente pela humanidade. Se a aprendizagem não ocorre de modo espontâneo nem por meio biológico, os indivíduos precisam ser educados. Daí a importância da escola como lugar privilegiado do ensino sistemático da cultura humana, e a relevância do professor como sujeito que ensina, transformando os alunos e a si mesmo.

Sobre a educação profissional técnica de nível médio (EPTNM), essa modalidade de ensino possui uma série de características que lhe dão especificidade no contexto da educação escolar. De modo sucinto, a EPTNM visa ao preparo para o exercício da cidadania e à qualificação para o trabalho, configurando-se essencial como política pública, uma vez que objetiva garantir o direito à educação e, concomitante, ao trabalho.

Machado (2008, p. 16) afirma que a especificidade primeira da educação profissional é a tecnologia, tida como "[...] uma ciência transdisciplinar das atividades humanas de produção, do uso dos objetos técnicos e dos fatos tecnológicos". Frente a isso, Machado (2008, p. 16) ressalta que:

\footnotetext{
É próprio do ensinar-aprender tecnologia e, portanto, da docência na educação profissional tratar da intervenção humana na reorganização do mundo físico e social e das contradições inerentes a esses processos, exigindo discutir questões relacionadas às necessidades sociais e às alternativas tecnológicas.
}

Como expõe Machado (2008, p. 17), o desafio de atuar na educação profissional devese ao fato de que, em cada modalidade, o professor precisa estar disposto a uma atuação 
didática e pedagógica diferente. Por exemplo: na modalidade técnica de nível médio, o professor precisaria, para cada forma, desenvolver capacidades diferentes, a saber:

\begin{abstract}
a) no ensino técnico integrado ao médio, ele deve saber integrar os conhecimentos científicos, tecnológicos, sociais e humanísticos, que compõem o núcleo comum de conhecimentos gerais e universais, e os conhecimentos e habilidades relativas às atividades técnicas de trabalho e de produção relativas ao curso técnico em questão; b) no ensino técnico concomitante ao médio, ele deve saber articular o planejamento e o desenvolvimento dos cursos, de modo a aproveitar oportunidades educacionais disponíveis; e c) no ensino técnico subsequente ao médio, ele deve saber lidar com um alunado heterogêneo que já concluiu o ensino médio e reforçar a formação obtida na educação básica paralelamente ao desenvolvimento dos conteúdos específicos à habilitação (MACHADO, 2008, p. 17, grifo nosso).
\end{abstract}

Em todas essas formas da educação profissional, segundo Machado (2008), o professor deveria ser um profissional com disposição para refletir, pesquisar, trabalhar em coletivo, efetivar ações críticas e cooperativas, compreender o mundo do trabalho, entender a função do docente, se atualizar em conhecimentos na área de formação específica e na área pedagógica.

Além disso, a autora afirma que o professor deve ser capaz de trabalhar tendo em vista a formação humana e integral dos seus alunos, isto é, uma formação em que os alunos se percebam sujeitos da sua história e adquiram compreensão crítica sobre o mundo do trabalho, as organizações sociais, o progresso tecnológico, e sobre outros fatores que caracterizam a realidade na qual os sujeitos estão inseridos.

Diante disso, Machado (2008) defende que a especificidade da educação profissional implica na especificidade da formação e da atuação dos docentes para essa área. Assim, as formações específicas nessa área podem contribuir para a reflexão sobre as práticas de ensino. Moura (2008) assevera que a formação docente para a atuação na educação profissional precisa habilitar os professores para além da aquisição de técnicas didáticas de transmissão de conteúdo, devendo, "[...] privilegiar a formação no âmbito das políticas públicas do país [...] de modo que se deve priorizar mais o ser humano do que, simplesmente, as relações de mercado e o fortalecimento da economia" (MOURA, 2008, p. 30).

Diante do exposto, o professor precisaria de uma formação que o possibilitasse dominar conhecimentos específicos da área profissional em que atuam, para que pudessem repassar esses conhecimentos a seus alunos de modo didático-políticopedagógico, sem deixar de estabelecer diálogos com a sociedade e com o mundo do trabalho.

Moura (2014) defende que tanto professores licenciados, como bacharéis precisam de uma formação complementar nessa área. Isso se deve ao fato de que os licenciados possuem uma formação básica de matemática, química, língua portuguesa etc., que dá alicerce para atuarem no ensino propedêutico, mas lhes falta uma formação específica para trabalhar na educação profissional. Com efeito, muitos professores licenciados possuem dificuldades em relacionar sua disciplina de ensino aos conteúdos profissionais. Da mesma 
forma, aos bacharéis (caso, por exemplo, dos engenheiros) e tecnólogos falta uma formação docente para atuar na educação em geral: propedêutica e profissional.

A falta, no Brasil, de políticas públicas de formação docente específica para a educação profissional, permite uma regulamentação fragmentada e emergencial, muitas vezes ajustada ao modo de produção. Assim, conforme Moura (2014), o papel do professor na educação profissional tende a se centralizar mais na dimensão econômica e menos na humana, o que pode reduzir a docência à função de formar pessoas com competências técnicas para a empregabilidade e para o mercado.

Para um trabalho emancipatório, como sugerem autores mencionados anteriormente, a centralidade da formação dos indivíduos deve estar na dimensão do ser humano, que prevê a educação como direito humano e o trabalho como princípio educativo. No contexto da educação profissional, a dimensão do ser humano é essencial para se construir uma educação que vise à formação de seres humanos e não à formação exclusiva de mão de obra.

Nesse sentido, esse aporte teórico contribui para a compreensão de um papel da docência que ultrapassa a transmissão de conhecimentos e de técnicas para o emprego/mercado. Para tanto, os autores ressaltam que é importante que o professor tenha não só uma formação tecnológica, mas também uma formação pedagógica e política. Essas reflexões consideram o professor como um sujeito fundamental no processo educativo, uma vez que sua função é desenvolver atividades de ensino, orientando a atividade de aprendizagem dos alunos.

\section{As especificidades da Rede Federal de Educação, Ciência e Tecnologia e suas implicações na docência}

A Rede Federal e seus Institutos Federais (IFs) foram consolidados com a Lei no 11.892, de 29 de dezembro de 2008 (BRASIL, 2008), no governo de Luiz Inácio Lula da Silva. Todavia, a educação profissional propiciada por esses institutos possui uma história que remonta ao século passado, pois grande parte das instituições da Rede Federal tiveram origem nas escolas de Aprendizes Artífices, criadas em 1909, no período em que Nilo Peçanha era presidente da República.

As escolas de Aprendizes Artífices surgiram com a finalidade de promover uma educação instrumental com foco nos sujeitos das classes proletárias, "[...] mediante o preparo técnico para o trabalho, afastando-os da ociosidade, da ignorância, do vício e do crime, ou seja, tornando-os, na compreensão do legislador, cidadãos úteis à Nação" (AZEVEDO; SHIROMA; COAN, 2012, p. 28).

Pena (2014) relata que, até chegar aos dias atuais como Institutos Federais, as escolas de Aprendizes Artífices passaram por várias mudanças, decorrentes das reformas na educação profissional no Brasil. Em 1942, foram transformadas em escolas Industriais e 
Técnicas. Em 1959, se constituíram Escolas Técnicas. Em 1978, se configuraram Centros Federais de Educação Tecnológica (CEFETs).

A criação da Rede Federal e de seus IFs, em 2008, foi fundamental para a expansão da educação profissional pública federal em todo o território brasileiro. Essa legislação permitiu a criação de $38 \mathrm{IFs}$, com 314 campi espalhados por todo o Brasil. $\mathrm{O}$ artigo $1^{\circ} \mathrm{da}$ Lei $n^{\circ}$ 11.892/2008 (BRASIL, 2008) determina as instituições que compõem a Rede Federal; são elas:

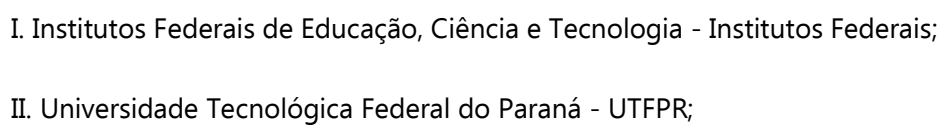

O artigo $2^{\circ}$ da mesma lei definiu os IFs como "[...] instituições de educação superior, básica e profissional, pluricurriculares e multicampi, especializados na oferta de educação profissional e tecnológica nas diferentes modalidades de ensino" (BRASIL, 2008).

A legislação orienta ainda que $50 \%$ das vagas de educação profissional devem ser ofertadas na forma integrada com o ensino médio; e $20 \%$ das vagas devem ser destinadas às licenciaturas, bem como a programas especiais de formação pedagógica, com vistas à formação de professores para a educação básica. Os IFs podem oferecer também cursos de graduações tecnológicas, especializações, mestrados e doutorados, nas modalidades a distância e/ou presencial.

Isso significa que os IFs possuem uma organização pedagógica verticalizada, podendo oferecer diferentes níveis e modalidades de educação, o que não faz parte da história das antigas escolas de Aprendizes Artífices que ofertavam, prioritariamente, cursos de nível médio. Essa modificação agrega aos IFs nova identidade e função social. Assim sendo, no artigo $6^{\circ}$ da Lei 11.892/2008 (BRASIL, 2008), ficam deliberadas as finalidades e as características dos IFs:

\footnotetext{
I - ofertar educação profissional e tecnológica, em todos os seus níveis e modalidades, formando e qualificando cidadãos com vistas na atuação profissional nos diversos setores da economia, com ênfase no desenvolvimento socioeconômico local, regional e nacional;

II - desenvolver a educação profissional e tecnológica como processo educativo e investigativo de geração e adaptação de soluções técnicas e tecnológicas às demandas sociais e peculiaridades regionais;

III - promover a integração e a verticalização da educação básica à educação profissional e educação superior, otimizando a infraestrutura física, os quadros de pessoal e os recursos de gestão;

IV - orientar sua oferta formativa em benefício da consolidação e fortalecimento dos arranjos produtivos, sociais e culturais locais, identificados com base no mapeamento das
} 
potencialidades de desenvolvimento socioeconômico e cultural no âmbito de atuação do Instituto Federal;

V - constituir-se em centro de excelência na oferta do ensino de ciências, em geral, e de ciências aplicadas, em particular, estimulando o desenvolvimento de espírito crítico, voltado à investigação empírica;

VI - qualificar-se como centro de referência no apoio à oferta do ensino de ciências nas instituições públicas de ensino, oferecendo capacitação técnica e atualização pedagógica aos docentes das redes públicas de ensino;

VII - desenvolver programas de extensão e de divulgação científica e tecnológica;

VIII - realizar e estimular a pesquisa aplicada, a produção cultural, o empreendedorismo, o cooperativismo e o desenvolvimento científico e tecnológico;

IX - promover a produção, o desenvolvimento e a transferência de tecnologias sociais, notadamente as voltadas à preservação do meio ambiente.

Em tela as finalidades dos IFs, é possível notar o projeto educacional da Rede Federal, que tem o objetivo de contribuir com o desenvolvimento socioeconômico local, regional e nacional, em prol do progresso da sociedade. Desse modo, é pressuposto que essa rede se propõe a promover uma formação cidadã que visa à autonomia e à emancipação dos sujeitos, ao mesmo tempo em que implica numa formação laboral, necessária para o fortalecimento dos arranjos produtivos. Para tanto, o artigo $7^{a}$ da Lei que institui a Rede Federal (BRASIL, 2008) determina os seguintes objetivos para os IFs:

I - ministrar educação profissional técnica de nível médio, prioritariamente na forma de cursos integrados, para os concluintes do ensino fundamental e para o público da educação de jovens e adultos;

II - ministrar cursos de formação inicial e continuada de trabalhadores, objetivando a capacitação, o aperfeiçoamento, a especialização e a atualização de profissionais, em todos os níveis de escolaridade, nas áreas da educação profissional e tecnológica;

III - realizar pesquisas aplicadas, estimulando o desenvolvimento de soluções técnicas e tecnológicas, estendendo seus benefícios à comunidade;

IV - desenvolver atividades de extensão de acordo com os princípios e finalidades da educação profissional e tecnológica, em articulação com o mundo do trabalho e os segmentos sociais, e com ênfase na produção, desenvolvimento e difusão de conhecimentos científicos e tecnológicos;

V - estimular e apoiar processos educativos que levem à geração de trabalho e renda e à emancipação do cidadão na perspectiva do desenvolvimento socioeconômico local e regional; e

VI - ministrar em nível de educação superior.

No que se refere à organização dos IFs, a legislação vigente determina a estrutura pluricurricular e multicampi. Juridicamente, a Rede Federal é uma autarquia mantida pelo orçamento público central, que possui um ensino de natureza pública e gratuita. Sob a responsabilidade da União, os IFs são fiscalizados pela Secretaria de Educação Profissional e Tecnológica (SETEC) do Ministério da Educação (MEC). 
Especificamente sobre o Instituto Federal do Espírito Santo (IFES), sabe-se que a primeira unidade de ensino foi oficializada em 23 de setembro de 1909 ainda como Escola de Aprendizes Artífices do Espírito Santo, em Jucutuquara, bairro da capital Vitória (IFES, s.d.).

O campus de Vitória é oficialmente considerado, portanto, a primeira escola federal do estado capixaba. A seguir, as nomenclaturas que a instituição recebeu ao longo de sua existência:

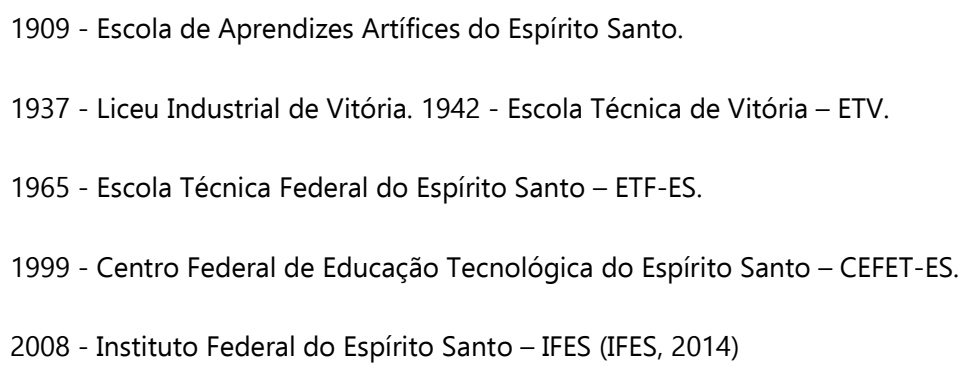

Desde 1909, várias escolas federais foram constituídas no estado capixaba. Com a criação da Rede Federal, em 2008, essas escolas passaram a integrar uma estrutura única, consolidando-se no IFES. A partir de então, outros campi desse Instituto foram criados no estado.

Atualmente, há 22 campi localizados em todas as microrregiões capixabas: Metropolitana; Central Serrana; Sudoeste Serrana; Litoral Sul; Central Sul; Caparaó; Rio Doce; Centro-Oeste; Nordeste e Noroeste. Além disso, o IFES possui 35 polos de educação a distância no estado, coordenados pelo Centro de Referência em Formação e em Educação a Distância - CEFOR (IFES, s.d.).

O IFES é uma autarquia federal vinculada ao MEC por meio da SETEC. A instituição possui autonomia administrativa, patrimonial, financeira, didático-pedagógica e disciplinar e segue a estrutura pluricurricular e multicampi, conforme orienta a legislação que instituiu a Rede Federal. Submetida à Lei no 11.892/2008 (BRASIL, 2008), a atuação do IFES deve ter como foco o desenvolvimento local e regional. Desse modo, a instituição oferta cursos de educação profissional em todos os níveis e modalidades, considerando os arranjos produtivos locais. Atualmente, a instituição oferece, aproximadamente, 90 cursos técnicos de nível médio, 50 de graduação, 15 de especializações e 10 de mestrados, atendendo cerca de 17 mil alunos (INSTITUTO FEDERAL DO ESPÍRITO SANTO, s.d.).

Como dito, o IFES é normatizado por uma legislação federal. Além das leis que estão na sua origem e determinam sua gestão e funcionamento (Decreto $n^{\circ} 7.566 / 1909$ e Lei $n^{\circ}$ 11.892/2008), essas instituições obedecem à normatização da Educação Geral, como a LDB n. 9.394/96 (BRASIL, 2018), dentre outras e, mais especificamente, às Leis da Educação Profissional, como o Decreto $n^{\circ}$ 5.154/2004 (BRASIL, 2004), o Decreto $n^{\circ}$ 5.840/2006 (BRASIL, 2006) e a Resolução $n^{\circ}$ 06/2012 (BRASIL, 2012). Essas legislações definem alguns limites e diretrizes para a formação e a atuação dos docentes nesse estabelecimento. 
No estado capixaba, o IFES (criado em 1909) é uma instituição tradicional na oferta de educação profissional e possui reconhecimento e prestígio social. Essas características configuram uma identidade institucional que pode refletir na docência. De modo geral, ser professor da rede federal tem um status prestigiado na sociedade. Os professores são juridicamente reconhecidos como pertencentes à categoria do magistério e possuem condição de servidores públicos.

Por conseguinte, o IFES possui um modo de ensinar construído ao longo da sua história. O profissional docente que se insere nessa instituição encontra um modus operandi bastante arraigado, produto do conjunto de valores sedimentados no decorrer dos anos e consolidado nas suas culturas organizacional e escolar. Como já exposto, os IFs possuem características específicas: se configuram numa autarquia, pertencem à Rede Federal, possuem natureza pública e gratuita do ensino, seus serviços são mantidos pelo orçamento público central.

Mediante entrevista, os professores afirmaram que estão satisfeitos com as condições de trabalho proporcionadas pela Rede Federal. No que se refere à identidade dos docentes, grande parte dos sujeitos desta pesquisa se considera pertencente à categoria do magistério; e uma pequena parte se identifica como engenheiro. Logo, mesmo numa instituição onde o magistério possui prestígio social, alguns profissionais tendem a não se identificarem nessa categoria, configurando-se um conflito entre ser engenheiro e ser professor.

Esse conflito deve-se ao fato de que muitos professores, na educação profissional, possuem formação na área tecnológica em que atuam. No caso do curso Técnico em Mecânica do IFES/Campus Vitória, grande parte dos docentes é composta de engenheiros com doutorado na área tecnológica. Assim, mesmo atuando na docência, alguns professores se identificam profissionalmente conforme sua formação acadêmica. Todavia, é importante ressaltar que esse sentimento de não identificação com a profissão docente pode, em determinadas situações, contribuir para o não compromisso com a função política e social que o professor precisa assumir.

Sendo o IFES uma instituição estatal, com gestão pública, seus serviços tendem a ser ofertados como um direito social, de maneira gratuita. Desse modo, o aluno, ao ser selecionado, é um detentor da matrícula conquistada por meios sociais e de mérito. Nesse caso, a relação professor-aluno-instituição dá-se mediante o direito social, produzindo consequências para a formação e a atuação docente.

Todavia, o acesso ao IFES não possui caráter universal. Em outras palavras, a matrícula não é totalmente acessível, posto que o acesso é definido com base em critérios diferentes de seletividade social, econômica e meritocrática. Logo, para ingressar nos cursos ofertados por esta instituição, o aluno precisa realizar um processo seletivo, a partir da realização de prova objetiva. Normalmente, essa seleção acontece por meio de concurso público multicampi, organizado pelo próprio IFES. 
Com efeito, nessa instituição, o docente encontra um público e uma relação pedagógica diferente dos encontrados nas escolas públicas estaduais e municipais, e mesmo das escolas privadas. Isto significa que, apesar de o IFES estar cada vez mais acessível devido ao sistema de cotas e a sua expansão territorial, os alunos dessa instituição são típicos e suas formas de organização são singulares em relação aos outros espaços escolares em geral.

Para melhor conhecimento do perfil dos alunos, do índice de procura pelo curso técnico nas modalidades concomitante/subsequente e do fluxo escolar, no contexto do curso técnico em mecânica do IFES/Campus Vitória, apresentamos a Tabela 1.

Tabela 1 - Perfil dos alunos, índice de procura e o fluxo escolar do curso técnico em mecânica (concomitante e subsequente) relativos ao ano de 2016.

\section{Dados sobre os alunos}

Matriculados

Renda per capita

Gênero

Faixa etária

Procedência escolar
222

\section{IFES - Campus Vitória}

70\% possuem entre 1 a 3 salários mínimos

86\% são homens

$14 \%$ são mulheres.

A maioria possui idades entre 18 a 29 anos.

$76 \%$ - escola pública;

$24 \%$ - escola privada.

Procura - candidato por vaga

Média de 7,3 nos $1^{\circ}$ e $2^{\circ}$ semestres

Fonte: elaborado pelos autores a partir de dados produzidos em entrevistas, realizadas em 2017.

De acordo com a coordenação pedagógica do IFES/Campus Vitória, conforme exposto na Tabela 1, foram matriculados 222 alunos no curso Técnico em Mecânica, no ano de 2016. Desses, aproximadamente $70 \%$ possuem renda per capita entre 1 e 3 salários mínimos; a maioria é jovem, com idades entre 18 e 29 anos; $86 \%$ são homens e $14 \%$ mulheres; $74 \%$ são procedentes de escola pública e $24 \%$ de escola privada. No que se refere à relação candidato por vaga, a modalidade concomitante/subsequente ao ensino médio teve média de 7,3 (por vaga) de concorrência no primeiro e segundo semestre de 2016 (INSTITUTO FEDERAL DO ESPÍRITO SANTO, s.d.).

Em suma, observa-se que o perfil dos alunos do curso Técnico em Mecânica, das modalidades subsequentes e concomitantes, é composto por uma maioria que pertence à 
classe social média-baixa, do gênero masculino, jovem, proveniente de escola pública. Os professores dessa área afirmam que o perfil dos alunos traz implicações para o trabalho docente.

Segundo os professores, atualmente, o IFES/Campus Vitória possui um público muito diverso, atendendo tanto a alunos provenientes de escolas particulares, como de escolas públicas e pertencentes às diversas classes sociais. Essa diversidade do perfil de alunos perpassa as modalidades de educação profissional ofertadas pela instituição e causa impactos na docência.

De acordo com os professores, a modalidade integrada tende a ter um público mais escolarizado e com maior nível de renda; porém, nas modalidades subsequente e concomitante, os professores encontram alunos menos escolarizados e com menor nível de renda. Sendo assim, dos professores é exigido um esforço de realização de um trabalho diferenciado em cada uma das modalidades da educação profissional ofertada pela instituição, tendo em vista as necessidades dos educandos. Todavia, isso não é uma tarefa fácil.

Segundo o professor $\mathrm{ST}^{1}$, "[...] estávamos acostumados a trabalhar com a modalidade integrada; com os melhores alunos, que passavam por um filtro forte através de um processo seletivo bem concorrido". Contudo, esse professor afirma que, com a oferta cada vez mais ampla das modalidades subsequente e concomitante, um novo perfil de alunos começou a se configurar dentro do instituto, trazendo impactos para o trabalho docente. Especificamente nas modalidades subsequente e concomitante, conforme diz o professor ST, "[...] a maioria dos alunos são concluintes ou estão cursando o ensino médio em escolas públicas, ou são alunos que estavam há bastante tempo fora da escola, ou que precisam conciliar trabalho e estudo". Esse mesmo professor ressalta que "[...] esses alunos chegam ao IFES apresentando bastantes dificuldades de conceitos e fundamentos que são importantes para compreensão do conhecimento técnico".

Nesse sentido, é possível compreender que um dos desafios para ensinar no curso Técnico em Mecânica (subsequente e concomitante) no contexto do IFES, Campus Vitória, está relacionado ao perfil dos alunos, que normalmente apresentam pouco conhecimento prévio dos saberes básicos (matemática, física e química), o que pode implicar em dificuldade de aprendizagem por parte dos alunos, e de ensino, por parte dos professores.

Para melhorar e facilitar o processo de ensino e aprendizagem, na opinião do professor ST, seria "[...] preciso proporcionar acolhimento melhor a esses alunos, uma assessoria mais atuante, ações educativas que permitam aos alunos superarem as suas dificuldades e o trabalho docente precisa ser adaptável e flexível".

\footnotetext{
${ }^{1}$ Sigla adotada para identificar o professor do curso Técnico em Mecânica do Ifes, Campus Vitória, mantendo a sua identidade em sigilo. Doravante, adotaremos o mesmo artifício para trazer as falas dos outros participantes desta pesquisa.
} 
No que se refere à organização pedagógica do IFES, é possível compreender algumas particularidades. O IFES possui uma estrutura pluricurricular e verticalizada que permite a oferta de cursos de educação profissional desde o nível médio até o nível superior (inclusive de pós-graduação). Portanto, a formação docente com cursos de licenciaturas, complementação pedagógica e pós-graduação (lato sensu e stricto sensu). integram a sua grade de oferta de cursos. Alguns autores, como Costa (2016), fazem críticas à obrigatoriedade da formação de professores nos Institutos Federais, defendendo que os IFs não possuem tradição na oferta desses cursos, o que torna essa atividade desafiadora para Rede Federal.

Como mencionado anteriormente, o IFES, organizado por Conselho Superior, Reitoria e campi, possui autonomia na gestão financeira, administrativa e pedagógica. Tutelado pelo Estado (União), a instituição tem liberdade para criar e oferecer os seus cursos, eleger sua liderança local (reitor e diretores), propor sua metodologia de ensino. Isso reflete na atuação dos servidores públicos, os quais, no seu ambiente de trabalho, podem, relativamente, fazer escolhas.

Sobre esse tema é interessante escutar o que os professores dizem a respeito de sua autonomia política e pedagógica dentro dessas instituições. Nesta pesquisa, a autonomia política remete à liberdade dos professores nas discussões políticas da escola, no sentido de expressarem suas opiniões e suas reflexões com a possibilidade de serem ouvidas e refletidas. A autonomia pedagógica diz respeito à liberdade que o professor possui para mobilizar, organizar e praticar a sua atividade pedagógica.

Entretanto, consideramos que essa última é sempre relativa, posto que a atuação docente é submetida às hierarquias que constituem esses espaços escolares. Nessa lógica, o trabalho docente precisa obedecer às obrigações previstas nas legislações educacionais, ao plano de curso, às diversas regras institucionais, bem como às normas curriculares (objetivos, metodologias, conteúdos) e, inclusive, à cultura organizacional de cada uma dessas instituições. Para aprofundar a especificidade e a singularidade da autonomia docente, passamos a analisar seus desdobramentos no IFES, considerando sua face política e pedagógica.

Especificamente sobre a autonomia política, o coordenador RB afirma: "[...] nós temos autonomia política aqui no Instituto Federal". O coordenador ressalta a atividade de eleição dos gestores como exemplo dessa autonomia: "[...] os nossos coordenadores, diretores, até o reitor são escolhidos pelos professores, servidores e alunos, em eleição".

A autonomia política no IFES decorre também do tipo de vínculo empregatício e da relação de trabalho; nesse caso, os professores têm a liberdade de se posicionar no ambiente de trabalho, sem riscos evidentes de repreensão ou punição, o que fica explícito no relato do professor ST: "[...] somos servidos públicos, temos estabilidade, temos salário, temos nossas disciplinas para dar conta, então, temos total liberdade para nos posicionar, falar, nos fazer ser ouvidos e não recebemos nenhuma penalidade direta por isso". 
Sobre a autonomia pedagógica, o professor AD afirma: "[...] temos autonomia pedagógica", e reitera que "[...] a forma como eu vou ensinar é livre, pois cada professor tem a sua própria maneira de ensinar". Contudo, o referido professor informa que, no planejamento, isso é relativo, pois "[...] os professores que ministram a mesma disciplina fazem o planejamento das aulas juntos para que exista certa padronização"; além disso, o professor $A D$ afirma que tudo isso é feito "[...] com a ajuda da pedagoga".

Outro professor do IFES, a quem identificamos como RG, ao informar sobre essa mesma autonomia, afirma: "[...] quando eu entro na sala para ministrar uma aula, eu me viro, eu tenho plena autonomia"; porém, informa que, no caso dele, também "[...] a pedagoga faz as suas interferências, principalmente quando as coisas saem do que é comum na escola", ou seja, "[...] a pedagoga faz o acompanhamento dos processos e dos resultados".

Contudo, isso não significa que os professores estão submetidos aos pedagogos. Ao contrário disso, no depoimento do coordenador de curso RB, fica claro que "[...] no dia a dia, o professor pode executar, ou não, o planejamento feito junto com a pedagoga, e a execução, ou não, do planejamento é uma coisa que nem sempre a pedagoga consegue controlar".

Como é possível notar nos depoimentos dos professores do IFES, devido ao caráter público do vínculo profissional, os educadores dessa instituição tendem a ter um espaço relativamente amplo e flexível para atuar conforme suas escolhas profissionais e seus princípios pedagógicos e didáticos, bem como para manifestar seu posicionamento político.

Portanto, esse debate permite a compreensão do trabalho docente como uma atividade complexa e intelectual cuja característica fundante é a autonomia. E é essa autonomia que forja a identidade profissional do professor. Isso significa que as características da instituição tendem a estabelecer graus menores ou maiores de liberdade de atuação do professor, mas preserva sua identidade docente.

Nessa direção, convém destacar que os professores são sujeitos ativos no processo educativo. Sendo assim, ainda que as prescrições institucionais possam reduzir a autonomia dos docentes, não são capazes de impedir sua existência, posto que a autonomia é inerente ao trabalho docente. No cotidiano escolar, os professores escolhem seus métodos e sua didática de ensino, privilegiam determinados procedimentos, selecionam conteúdo a ser ministrado e/ou fazem adaptações conforme suas necessidades e dificuldades em busca de atingir seus objetivos, que nem sempre são semelhantes aos objetivos das instituições.

Nos documentos oficiais do IFES nota-se que as finalidades e os objetivos institucionais incluem, explicitamente, elementos relacionados ao desenvolvimento da sociedade e à formação de cidadãos. Não há uma vinculação direta com as empresas/ indústrias; por ser uma entidade pública, seu compromisso primeiro deve ser com a 
sociedade. Sendo assim, o professor da rede federal possui certa liberdade para criar práticas educativas cujas finalidades estão para além de formar para o mercado.

É evidente que o IFES estabelece seus próprios objetivos e suas finalidades, que constituem sua identidade institucional. Essa identidade tende a constituir o trabalho educativo dos docentes e, inclusive, a identidade dos educadores. Os discursos das instituições sobre suas finalidades e objetivos no campo da educação, de certo modo, refletem nos depoimentos dos professores, sujeitos desta pesquisa, como se pode observar nos relatos a seguir.

Questionados sobre qual seria a função social da instituição de ensino e o papel da educação profissional, os docentes do IFES ofereceram as seguintes respostas:

A função principal do IFES é formar cidadãos críticos, voltada não só na formação para o trabalho, mas para a vida (Prof. AD).

A gente, no IFES, tem um lema muito interessante: formar para a vida [...]. A missão que temos há bastante tempo é essa: formar o cidadão pleno para a vida. E vejo que a maioria dos meus colegas, professores, segue ou tenta trabalhar nessa direção (Prof. NS).

O IFES propicia a formação profissional científica e tecnológica, não só como o foco na formação técnica, mas também na formação humana. Isso está nos documentos oficiais da instituição e eu acredito que a gente faz isso na prática educativa. A formação humana e cidadã é muito importante para a gente (Coord. RB).

A função da educação profissional é formar um profissional capaz para o trabalho, mas formar também um cara que compreende criticamente os processos da realidade onde ele vivência (Prof. NS).

A função da educação profissional é desenvolver a capacitação técnica e a formação cidadã nos alunos. A questão da cidadania permite o aluno compreender que só saber apertar parafuso não é suficiente para uma atuação significativa no posto de trabalho e na sociedade (Prof. ST).

Entendo que a educação profissional permite aos alunos adquirir conhecimentos de uma profissão e, mais do que isso, permite o desenvolvimento do senso crítico, ou melhor, a formação de cidadãos que não aceitam qualquer coisa, pois são capazes de atuar de modo crítico no contexto do trabalho e no contexto social (Prof. AD).

Para os professores do IFES, a função dessa instituição não visa somente à formação de pessoas para atender às demandas do mercado, mas também à formação cidadã e humana dos educandos para uma atuação significativa na sociedade, o que inclui o ambiente de trabalho, durante toda a sua vida.

Nesta pesquisa, no que se refere à função social da instituição e da educação profissional, foi possível perceber uma aproximação entre os discursos institucionais apregoados nos documentos legais - e os discursos dos docentes - revelados nas entrevistas semiestruturadas. Isso permite compreender a relação entre a identidade das instituições e a de seus professores. É importante ressaltar que a maneira de conceber o papel social da educação tende a influenciar a prática de ensino, como explica Saviani (2007). 
Com esse entendimento, é possível inferir que a instituição de ensino que concebe a educação meramente para atender ao mercado, ou para conquistar a empregabilidade, tende a orientar o trabalho educativo com o objetivo de efetivar essas prerrogativas. $\mathrm{Na}$ mesma lógica, quando se compreende que o ensino deve pautar-se no aspecto éticopolítico, tende a orientar o desenvolvimento do processo educativo para além dessas prerrogativas, tendo em vista a emancipação dos sujeitos.

No caso do IFES, é possível compreender a sua posição estratégica na sociedade, pois além de servir aos interesses do capital, também é demandado pelos trabalhadores que veem na formação profissional um caminho para a inserção e ascensão social. Desse modo, é possível compreender como a educação profissional é atravessada pelos muitos projetos que se encontram em disputa na sociedade e, nessa lógica, ficam evidentes os desafios para atuação docente nessa modalidade.

\section{Considerações finais}

O IFES foi, inicialmente, criado para propiciar a educação profissional, sobretudo, de nível médio. Atualmente, na sociedade capixaba, é uma entidade de tradição, de referência e de prestígio social nessa modalidade de ensino. A docência na educação profissional, no contexto do IFES, é submetida aos ditames institucionais e, assim, fundamentada na sua identidade e na sua função social, a instituição tende a conformar o trabalho docente segundo as suas prerrogativas.

A pesquisa com os professores do curso técnico em mecânica do IFES/Campus Vitória, aponta que o trabalho docente na instituição, o que nos possibilita inferir como o trabalho docente é complexo e dinâmico, e é sua característica fundante a autonomia, que permite ao educador tanto trabalhar na perspectiva de cumprir as prerrogativas das instituições escolares, como realizar um trabalho diferenciado, com ou sem compromisso com as normas institucionais. Tal autonomia forja a identidade profissional do professor. Isto significa que as características da instituição de ensino tendem a estabelecer graus menores ou maiores de liberdade de atuação do docente, mas preserva a identidade dele.

Como pode ser observado ao longo desta pesquisa, os ditames apregoados pelo IFES favorecem um ensino na perspectiva da formação humana, que valoriza a emancipação dos sujeitos. Por conseguinte, a prática pedagógica dos professores tende a caminhar nessa direção, na perspectiva da formação humana e integral. Contudo, o trabalho dos professores não segue uma uniformidade e, assim, é possível ter um grupo de professores que se preocupa em promover uma educação profissional articulada e integrada, no sentido da formação humana, mas também outro grupo que tenda a não seguir nessa direção, evidenciando-se a autonomia por parte dos professores da rede federal, no que se refere ao desenvolvimento de suas atividades de ensino.

Frente a essas considerações, é possível compreender que a educação profissional é atravessada pelas muitas concepções que se encontram em disputa na sociedade. Seu 
resultado é uma formação de trabalhadores que, por um lado, pode estar associada aos interesses do mercado e, por outro, pode visar às necessidades de formação humana desses trabalhadores. Assim sendo, o IFES, ao mesmo tempo em que é demandado pelo capital, também é considerado pelos trabalhadores um espaço privilegiado para formação profissional, que permite a inserção e ascensão na sociedade. Portanto, este estudo demonstra a especificidade da educação profissional e do trabalho docente nessa modalidade.

Com efeito, o trabalho docente na educação profissional se vê em meio às demandas de formação para o mercado, mas também deve se ancorar na função da emancipação desses trabalhadores. Essas contradições atravessam a atuação docente na educação profissional exigindo um esforço político e pedagógico dos profissionais envolvidos, que precisam, autonomamente, escolher como atuar nesse processo. Dessa forma, a atividade do professor faz toda a diferença na formação dos sujeitos; o professor, na função de mediador e orientador do processo de ensino e aprendizagem, pode relativizar a formação para o mundo do trabalho, isto é, não restringir suas práticas de ensino às demandas do mercado consoante à lógica do capital, mas sim, propiciar uma formação humana, com vistas à liberdade, à autonomia e à emancipação dos sujeitos. Em resumo, a partir de um trabalho dialético, o professor pode executar uma atividade flexível, que ultrapasse a lógica do capital.

\section{Referências}

AZEVEDO, L. A.; SHIROMA, E. O.; COAN, M. As políticas públicas para a educação profissional e tecnológica: sucessivas reformas para atender a quem. Boletim Técnico do Senac, v. 38, n. 2, p. 27-40, 2012. Disponível em: <http://www.bts.senac.br/index.php/bts/article/view/164 z. Acesso em: 04 jul. 2017.

BRASIL. Lei $n^{\circ}$ 9.394, de 20 de dezembro de 1996. Estabelece as diretrizes e bases da educação nacional. Diário Oficial da União, Brasília, DF, 23 dez. 1996. Disponível em: <http://www.planalto.gov.br/ccivil_03/leis/L9394.htm>. Acesso em: 20 jan. 2017.

BRASIL. Lei $n^{\circ}$. 11.892, de 29 de dezembro de 2008. Institui a Rede Federal de Educação Profissional, Científica e Tecnológica, cria os Institutos Federais de Educação, Ciência e Tecnologia, e dá outras providências. Diário Oficial da União, Brasília, DF, 30 dez. 2008b. Disponível em: <http://www.planalto.gov.br/ccivil_03/_Ato20072010/2008/Lei/L11892.htm>. Acesso em: 10 jul. 2017.

BRASIL. Decreto $n^{\circ} 5.154$, de 23 de julho de 2004. Regulamenta o $\S 2^{\circ}$ do art. 36 e os arts. 39 a 41 da Lei $n^{\circ}$ 9.394, de 20 de dezembro de 1996, que estabelece as diretrizes e bases da educação nacional, e dá outras providências. Diário Oficial da União, Brasília, DF, 24 jul. 2004. Disponível em: <http://www.planalto.gov.br/ccivil_03/_ato20042006/2004/decreto/d5154.htm>. Acesso em: 15 mai. 2017. 
BRASIL. Decreto No 5.840, de 13 de julho de 2006. Institui, no âmbito federal, o Programa de Integração da Educação Profissional com a Educação Básica na Modalidade de Educação de Jovens e Adultos - PROEJA. Diário Oficial da União, Brasília, DF, 14 jul. 2006. Disponível em: <http://www.planalto.gov.br/ccivil_03/_Ato2004-2006/2006/Decreto/D5840.htm>. Acesso em: 15 mai. 2017.

BRASIL. Resolução CNE/CEB nº 06, de 20 de setembro de 2012. Define Diretrizes Curriculares Nacionais para a Educação Profissional Técnica de Nível Médio. Diário Oficial da União, Brasília, DF, 21 set. 2012. Disponível em: <http://portal.mec.gov.br/index.php?option=com_docman\&view=download\&alias=1166 3-rceb006-12-pdf\&Itemid=30192>. Acesso em: 21 jan. 2017.

COSTA, M. A. da. Políticas de formação de professores para a educação profissional: realidade ou utopia. Curitiba: Appris, 2016.

GOMES, H.M; MARTINS, H.O. A ação docente na educação profissional. São Paulo: Senac, 2004.

IFES. Plano de Desenvolvimento Institucional 2014/2 - 2019/1. Vitória: IFES, 2014.

IFES. Institucional: história. Disponível em:

<http://www.ifes.edu.br/institucional?showall=\&start=1>. Acesso em: 26 jun. 2017.

KUENZER, A. Z. A formação de professores para o ensino médio: velhos problemas, novos desafios. Educação e Sociedade. Campinas, V. 32, n. 116, p. 667-688, 2011. Disponível em: <http://www.scielo.br/pdf/es/v32n116/a04v32n116.pdf>. Acesso em: 17 out. 2016.

MACHADO, L. R. S. Diferenciais inovadores na formação de professores para a educação profissional. Revista Brasileira da Educação Profissional e Tecnológica, Brasília, v. 1, n. 1, p. 8-22, jun-2008. Disponível em: < portal.mec.gov.br/setec/arquivos/pdf3/rev_brasileira.pdf>. Acesso em: 27 nov. 2017.

MOURA, M. O. A Atividade pedagógica na teoria histórico-cultural. $2^{\mathrm{a}}$ Ed. Campinas, SP: Autores Associados, 2016.

MOURA, M. O. O Educador matemático na coletividade de formação: uma experiência com a escola pública. 2000. 131 f. Tese (Doutorado) - Faculdade de Educação da Universidade de São Paulo, São Paulo, 2000.

MOURA, D. H. A formação de docentes para a educação profissional e tecnológica. Revista Brasileira da Educação Profissional e Tecnológica, Brasília, v. 1, n. 1, p. 23-38, 2008. Disponível em: <http://portal.mec.gov.br/setec/arquivos/pdf3/rev_brasileira.pdf>. Acesso em: 17 maio 2016.

MOURA, D. H. A integração curricular da educação profissional com a educação básica na modalidade de jovens e adultos (Proeja). Cadernos de pesquisa em educação - PPGEUFES. v. 19, n. 39, p. 30-49, Vitória: PPGE, 2014. 
PENA, G. A. C. Docência na educação profissional e tecnológica: conhecimentos, práticas e desafios de professores de cursos técnicos na rede federal. 2014, 290f. Tese (Doutorado em Educação) - Programa de Pós-graduação em Educação, Universidade Federal de Minas Gerais: Faculdade de Educação, 2014.

SAVIANI, D. Trabalho e educação: fundamentos ontológicos e históricos. Revista Brasileira de Educação, [S.I.], $\quad$ v. 12 n. 34 jan./abr. 2007. Disponível em: <http://www.scielo.br/pdf/rbedu/v12n34/a12v1234.pdf>. Acesso em: 17 jan. 2017.

\section{Informações sobre os autores:}

\section{Tatiana das Merces}

Mestra em Educação pela Universidade Federal do Espírito Santo (UFES). Atua como professora de Língua Portuguesa na Secretaria de Estado de Educação do Espírito Santo (SEEduc/ES).

ORCID iD: http://orcid.org/0000-0002-4732-9423

E-mail: tatianadasmerces@gmail.com

\section{Marcelo Lima}

Doutor em Educação pela Universidade Federal Fluminense (UFF), com pós-doutorado em historiografia da educação profissional pela mesma universidade. Atua como docente do Departamento de Educação, Política e Sociedade do Centro de Educação da Universidade Federal do Espírito Santo (DEPS/CE/UFES), integra o quadro docente do Programa de PósGraduação em Educação da UFES; integra o Núcleo de Estudos, Documentação e Dados sobre Trabalho e Educação (NEDDATE/UFF), o Grupo de Pesquisa Projetos Integrados de Pesquisas sobre Trabalho, História, Educação e Saúde (THESE/UFF), o Grupo de Pesquisa Gestão, Trabalho e Avaliação Educacional e o Grupo de Pesquisa "EM pesquisa".

ORCID iD: http://orcid.org/0000-0002-7448-8366

E-mail: marcelo.lima@ufes.br

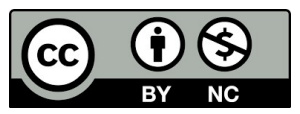

